\title{
The phenomenon of office objects of a new type
}

\author{
H. V. Lysiak \\ Lviv Polytechnic National University \\ Corresponding author. E-mail: galya27061995@gmail.com
}

Paper received 27.08.19; Accepted for publication 11.09.19.

\section{https://doi.org/10.31174/SEND-NT2019-206VII25-02}

Abstract. It is time to look at your usual office objects. As of 2019, more and more investors, from all over the world, are attracting their money into doing business in Ukraine, which means that the provision of domestic services must meet European standards. That is why it is worth looking at existing office facilities and determining what they will look like in the future.

Keywords: office, coworking, workers, research, improvement.

Introduction. The office real estate market is picking up a relatively new type of office space - coworkings. This type of office objects has long been popular in the world, but it has recently come to Ukraine. At this stage, offices of this type are gaining popularity in Kiev and moving to other areas, including the first city in line - Lviv.

A real estate company like WeWork, founded by Adam Newman, has networked with several WeCompany companies, WeGrow School in Chelsea, where children can chat, study and relax, as well as WeLive (they work in Washington and New York, he positioning itself as a hostel where you can stay for a few nights or relocate for a few months. Also in 2017, WeWork launched WeWork Wellness Fitness Direction. partners and project ideas. the company currently has more than 500 coworkings worldwide - from the US to Japan.

Literature review. The key aspects of coworking, which were considered through the analysis of the key advantages and disadvantages of this phenomenon, wrote in his article "Coworking: opportunities and obstacles" [1], about the office of a healthy person and six ways to arrange its boundaries, written in the electronic edition Archspeech [2]. Also, coworking in the context of business tourism development has been written by such authors as Blagoy V.V., Blaga V.V., Tikhomirov A.A. [3].

The purpose of this work is to define a functional and efficient office space for the integration of different business areas. Determine at what stage of development such office facilities are located in Ukraine.

Materials and methods. The basis of this research is a systematic approach that allows offices to be considered as necessary objects for the effective functioning of all employees. The research is the result of the collection of scientific information related to the bibliographic search for scientific information, the study of regulatory documents, the review of professional and fiction.

New type office solutions are changing the industry. The idea and business model of WeWork have revolutionized the world of office real estate. Large companies rent jobs because they like the atmosphere and facilities of the community, as well as the internal services and support that remove concerns from residents. Coworkings are fast growing and able to adapt to changes in the market. Previously, the network focused on freelancers, but now corporations are the main WeWork customers. According to Emergent Research, CB Insights reports that the entire field of coworking is moving from freelance services to working with small and medium-sized companies with up to 100 employees.
The main trends of the new type of offices are green building and environmental friendliness. Certification standards for sustainable and energy-efficient construction are being actively developed in the world. LEED and BREEAM evaluate buildings on a variety of factors, including environmental impacts. Eco-friendly construction involves reducing environmental damage in the process of erection and repair, saving electricity and water, improving the climate and improving the comfort of residents. The first energy-efficient business center in Ukraine was the ASTARTA Organic Business Center, Kiev. He has been certified by the BREEAM real estate appraisal system. Unfortunately, there are no own standards of green building in Ukraine yet, but with the rapid development of technologies and revaluation of values this may change. Projects that do not own, but lease, real estate have indicated that now offices are moving from office as physical space to office as service and have created a new business model - SPaaS (space as a service).

The success of various office real estate companies will increasingly depend on their ability to generate user experience.

Companies now and in the future need to analyze how people who rent space interact with it, what factors are missing, and what is hindering comfort and productivity in the workflow. There are already such analytical platforms. For example, Leesman takes into account employee feedback about the workplace and compares company performance against other organizations in the database.

However, employers are increasingly abandoning standard open-source offices where all employees work in the same room. Now they prefer planning that has a lot of focus on zoning and people sitting in small groups. There are six options to choose from: color (ACDF Architecture for Playster: contrasting colors, taken from the Playster company logo, create additional visual delineation of work areas); tunnel (Studio Octopi for 18 Feet \& Rising: the plywood tunnel, painted in black, separates the dining area from the two meeting rooms); Space Encounters for Joolz: space is delimited by three oblong greenhouses, they have an additional function - they can act as meeting rooms); flower boxes (Space Encounters for Synchroon: desktops, dining area and meeting rooms separated by meter-high partitions with plants); rubber curtains (Space Encounters for Flowpolis: movable translucent curtains made it possible to divide space without visually burdening the interior); "Populated wall" (Threefold Architects for Pocket Living: small workspaces are integrated into a 
"populated wall" that separates the main work area from the common corridor).
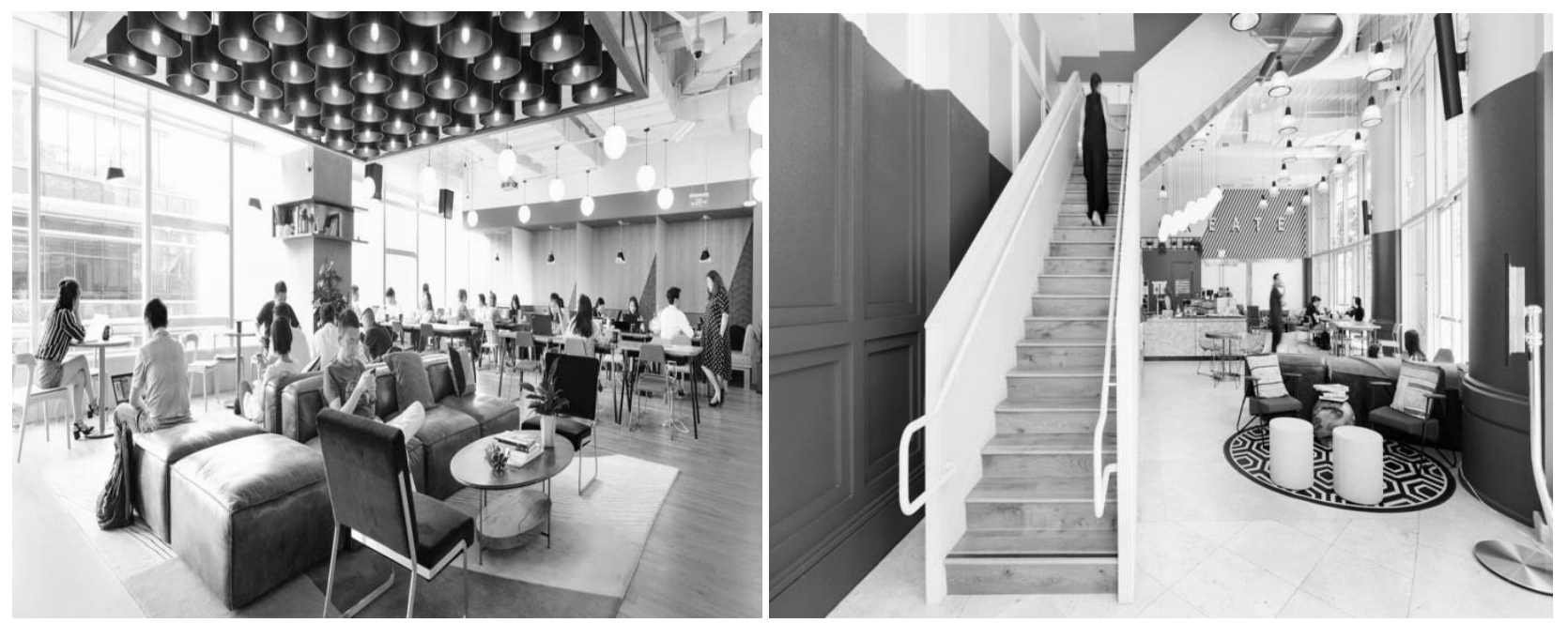

Picture 1. Example of designing a coworking room

Previously, it was believed that employees in opentype offices were more likely to contact. However, a study by Harvard University found that these types of offices interfere with communication, and in the open space, colleagues engage in live communications at $70 \%$ less often - instead, they prefer to correspond by mail or in messengers. Also, such offices prevent you from concentrating. In 2014, Steelcase surveyed 10,000 people and found that office workers lose about 86 minutes a day because they are distracted by noise. This, in turn, does not have the best effect on creativity - $65 \%$ of people in the creative professions demand silence (according to a WeTransfer 2018 survey) [2]. Many employers argue against open-type offices, including Simon Caspersen, cofounder of IKEA Space $10 \mathrm{Lab}$. In an interview with Dezeen, he said why the company decided to abandon the open plan: "It was stressful, you were constantly interrupted, and you did not feel that you did your job as well as possible." According to him, this also led to the fact that people either worked from home most of the time or stayed out of hours, because only then could they really focus on their tasks.

Results and discussion. The result of the study is an attempt to analyze at what stage office building in the world is currently developing and to draw a parallel with Ukrainian business real estate. With great social and productive potential, it is possible that in Ukraine, such type of office objects as coworkings will begin to develop rapidly, especially since this process has already begun in Kyiv today.

Conclusions. Office facilities are no longer places to work because society is moving toward collaboration. At the moment, these are platforms for collaborations, networking, business creation, and industry-changing solutions. One type contains an event area, office infrastructure, relaxation area. Now, Kiev is the most active city on the map of the domestic market and it is not surprising, because it always starts with the capital. Investors and developers are growing in interest in this area and the number of business deals is increasing. If you look at the statistics, the largest part, over $40 \%$, is occupied by the IT sector, in second place - the production one. As of 2019, demand exceeds supply - there are not enough quality solutions in the market.

To solve this situation, it is necessary to create spaces where companies will have access to cooperation, development opportunities and services: obtaining FOP, hiring, purchasing various office equipment, logistics and legal support. For example, as CEO and founder of the Creative States network Ilya Konigstein said, "Our idea is to create a network of large-scale office solutions for the creative class, to which we include IT companies, lawyers, advertisers, venture capital funds, young agricultural companies, and mature cooperation."

\section{REFERENSES}

1. Shwed V.V. Coworking: Opportunities and Obstacles // Electronic Scientific Professional Edition. Global and national problems of economy, 2015. Issue. 4 P. 1095-1099.

2. Office of a healthy person: 6 ways to arrange boundaries // URL: $\quad$ https://archspeech.com/article/ofis-zdorovogo-

3. Blagoy V.V., Blaga V.V., Tikhomirova A.O. Coworking in the Context of Business Tourism Development // Electronic Scientific Professional Edition. Global and national problems of economy, 2017. Issue. 16, P.. 119-121. 